\title{
GENERALIZED ALMOST AUTOMORPHIC AND GENERALIZED ASYMPTOTICALLY ALMOST AUTOMORPHIC SOLUTIONS OF ABSTRACT VOLTERRA INTEGRO-DIFFERENTIAL INCLUSIONS
}

\author{
MARKO KOSTIĆ
}

Abstract. The main aim of this paper is to investigate generalized almost automorphy and generalized asymptotical almost automorphy of solutions for certain classes of abstract Volterra integro-differential inclusions and abstract (semilinear) fractional differential inclusions in Banach spaces. We illustrate our abstract results with several examples and possible applications.

Mathematics subject classification (2010): 44A35, 42A75, 47D06, 34G25, 35R11.

Keywords and phrases: Abstract Volterra integro-differential inclusions, abstract fractional differential inclusions, semilinear fractional Cauchy inclusions, multivalued linear operators, generalized almost automorphy, generalized asymptotical almost automorphy.

\section{REFERENCES}

[1] S. ABBas, A note on Weyl pseudo almost automorphic functions and their properties, Math. Sci. (Springer), 6:29 (2012), 5 pp, doi : 10.1186/2251-7456-6-29.

[2] S. Abbas, V. Kavitha, And R. Murugesu, Stepanov-like weighted pseudo almost automorphic solutions to fractional order abstract integro-differential equations, Proc. Indian Acad. Sci. (Math. Sci.), 125 (2015), 323-351.

[3] M. Amerio And G. Prouse, Almost Periodic Functions and Functional Equations, Van NostrandReinhold, New York, 1971.

[4] J. Andres, A. M. Bersani, And R. F. GRAnde, Hierarchy of almost-periodic function spaces, Rend. Mat. Appl. 26 (2006), 121-188.

[5] W. Arendt, C. J. K. Batty, M. Hieber, And F. Neubrander, Vector-valued Laplace Transforms and Cauchy Problems, Birkhäuser/Springer Basel AG, Basel, 2001.

[6] E. BAzhlekova, Fractional evolution equations in Banach spaces, Ph. D. thesis, Eindhoven University of Technology, Eindhoven, 2001.

[7] F. Bedouhene, N. Challali, O. Mellah, P. Raynaud de Fitte, and M. SmaAli, Almost automorphy and various extensions for stochastic processes, J. Math. Anal. Appl. 429 (2015), 11131152 .

[8] A. S. Besicovitch, Almost Periodic Functions, Dover Publications Inc., New York, 1954.

[9] J. Blot, G. M. Mophou, G. M. N'GuÉrékAta, And D. Pennequin, Weighted pseudo almost automorphic functions and applications to abstract differential equations, Nonlinear Anal. 71 (2009), 903-909.

[10] S. Bochner, A new approach to almost periodicity, Proc. Nat. Acad. Sci. USA., 48 (1962), 2039_ 2043.

[11] D. BUgAJEWS KI AND T. DiAgAnA, Almost automorphy of the convolution operator and applications to differential and functional differential equations, Nonlinear Stud. 13 (2006), 129-140.

[12] R. W. Carroll and R. W. Showalter, Singular and Degenerate Cauchy Problems, Academic Press, New York, 1976.

[13] D. N. Cheban, Asymptotically Almost Periodic Solutions of Differential Equations, Hindawi Publishing Corporation, New York, 2009. 
[14] V. CASARInO, Almost automorphic groups and semigroups, Rend. Accad. Naz. Sci. XL Mem. Mat. Appl. (5), 24 (2000), 219-235.

[15] R. Cross, Multivalued Linear Operators, Marcel Dekker Inc., New York, 1998.

[16] C. Cuevas And C. LizAma, Almost automorphic solutions to a class of semilinear fractional differential equations, Appl. Math. Lett. 21 (2008), 1315-1319.

[17] T. Diagana, Almost Automorphic Type and Almost Periodic Type Functions in Abstract Spaces, Springer, New York, 2013.

[18] T. Diagana, G. M. N'GuÉRÉKATA, AND N. V. Minh, Almost automorphic solutions to evolution equations, Proc. Amer. Math. Soc. 132 (2004), 3289-3298.

[19] T. Diagana And G. M. N'GuÉRÉKATA, Almost automorphic solutions to semilinear evolution equations, Funct. Differ. Equ. 13 (2006), 195-206.

[20] T. DiAGANA AND R. AGARWAL, Existence of pseudo almost automorphic solutions for the heat equation with $S^{p}$-pseudo almost automorphic coefficients, Boundary Value Problems, vol. 2009, Article ID 182527, 19 pages, doi:10.1155/2009/182527.

[21] T. Diagana, V. Nelson, AND G. M. N'GuÉRÉKATA, Stepanov-like $C^{(n)}$-pseudo-almost automorphy and applications to some nonautonomous higher-order differential equations, Opuscula Math. 32 (2012), 455-471.

[22] H.-S. DING, J. LIANG, AND T.-J. XIAO, Almost automorphic solutions to nonautonomous semilinear evolution equations in Banach spaces, Nonlinear Anal. 73 (2010), 1426-1438.

[23] H.-S. Ding, J. LiAng, AND T.-J. XIAO, Some properties of Stepanov-like almost automorphic functions and applications to abstract evolution equations, Appl. Anal. 88 (2009), 1079-1091.

[24] H.-S. Ding, J. Liang, AND T.-J. XIAO, Almost automorphic solutions to abstract fractional differential equations, Advances Diff. Equ., vol. 2010, Article ID 508374, 9 pages, doi:10.1155/2010/508374.

[25] Z. FAN, J. LiAng, AND T.-J. XiaO, On Stepanov-like (pseudo)-almost automorphic functions, Nonlinear Anal. 74 (2011), 2853-2861.

[26] S. Fatajou, N. Van Minh, G. M. N'Guérékata, And A. Pankov, Stepanov-like almost automorphic solutions for nonautonomous evolution equations, Electron. J. Differential Equations 121 (2007), 1-11.

[27] A. Favini And A. Yagi, Degenerate Differential Equations in Banach Spaces, Chapman and Hall/CRC Pure and Applied Mathematics, New York, 1998.

[28] J. A. GOLDSTEIN AND G. M. N'GUÉRÉKATA, Almost automorphic solutions of semilinear evolution equations, Proc. Amer. Math. Soc. 133 (2005), 2401-2408.

[29] G. M. N'Guérékata, Almost Automorphic and Almost Periodic Functions in Abstract Spaces, Kluwer Acad. Publ., Dordrecht, 2001.

[30] G. M. N'GuÉRÉKATA AND M. Kostić, Generalized asymptotically almost periodic and generalized asymptotically almost automorphic solutions of abstract multi-term fractional differential inclusions, Abstract Appl. Anal., volume 2018, Article ID 5947393, 17 pages, https://doi.org/10.1155/2018/5947393.

[31] Y. Hino, T. Naito, N. V. Minh, And J. S. Shin, Almost Periodic Solutions of Differential Equations in Banach Spaces, Stability and Control: Theory, Methods and Applications 15, Taylor and Francis Group, London, 2002.

[32] M. Kostić, Abstract Volterra Integro-Differential Equations, Taylor and Francis Group/CRC Press/Science Publishers, Boca Raton, New York, 2015.

[33] M. Kostić, Abstract Degenerate Volterra Integro-Differential Equations: Linear Theory and Applications, Book Manuscript, 2016.

[34] M. Kostić, On almost periodic solutions of abstract semilinear fractional inclusions with WeylLiouville derivatives of order $\gamma \in(0,1]$, J. Math. Stat. 13 (2017), 240-250.

[35] M. Kostić, The existence and uniqueness of pseudo-almost periodic solutions of semilinear Cauchy inclusions of first order, Appl. Math. Comp. Sci. 2 (2017), 19-24.

[36] M. Kostić, Abstract degenerate fractional differential inclusions, Appl. Anal. Discrete Math. 11 (2017), 39-61.

[37] M. Kostić, Existence of generalized almost periodic and asymptotic almost periodic solutions to abstract Volterra integro-differential equations, Electron. J. Differential Equations, vol. 2017, no. 239 (2017), 1-30. 
[38] M. Kostić, Almost Periodic and Almost Automorphic Type Solutions of Abstract Volterra IntegroDifferential Equations, Book Manuscript, 2017.

[39] M. Kostić, Weyl-almost periodic solutions and asymptotically Weyl-almost periodic solutions of abstract Volterra integro-differential equations, J. Math. Anal. Appl., submitted.

[40] M. Kostić, The existence and uniqueness of almost periodic and asymptotically almost periodic solutions of semilinear Cauchy inclusions, Hacetepe J. Math. Stat., submitted.

[41] H. LeE AND H. AlKAhBy, Stepanov-like almost automorphic solutions of nonautonomous semilinear evolution equations with delay, Nonlinear Anal. 69 (2008), 2158-2166.

[42] M. Levitan and V. V. Zhikov, Almost Periodic Functions and Differential Equations, Cambridge Univ. Press, London, 1982.

[43] J. Liang, J. Zhang, AND T.-J. XIAO, Composition of pseudo-almost automorphic and asymptotically almost automorphic functions, J. Math. Anal. Appl. 340 (2008), 1493-1499.

[44] I. V. Melnikova And A. I. Filinkov, Abstract Cauchy Problems: Three Approaches, Chapman Hall/CRC Press, Boca Raton, 2001.

[45] J. Mu, Y. ZhoA, AND L. Peng, Periodic solutions and S-asymptotically periodic solutions to fractional evolution equations, Discrete Dyn. Nat. Soc. vol. 2017, Article ID 1364532, 12 pages, https://doi.org/10.1155/2017/1364532.

[46] F. PERIAGO AND B. STRAub, A functional calculus for almost sectorial operators and applications to abstract evolution equations, J. Evol. Equ. 2 (2002), 41-68.

[47] J. PRÜSS, Evolutionary Integral Equations and Applications, Birkhäuser-Verlag, Basel, 1993.

[48] A. ReIch, Präkompakte Gruppen und Fastperiodizität, Math. Z. 116 (1970).

[49] S. G. Samko, A. A. Kilbas, And O. I. Marichev, Fractional Derivatives and Integrals: Theory and Applications, Gordon and Breach, New York, 1993.

[50] G. A. SviridyuK AND V. E. Fedorov, Linear Sobolev Type Equations and Degenerate Semigroups of Operators, Inverse and Ill-Posed Problems (Book 42), VSP, Utrecht, Boston, 2003.

[51] R. TERRAS, Almost automorphic functions on topological groups, Indiana U. Math., J. 21 (1972).

[52] W. A. VeECH, Almost automorphic functions on groups, Amer. J. Math. 87 (1965), 719-751.

[53] W. A. VEECH, On a theorem of Bochner, Ann. of Math. 86 (1967), 117-137.

[54] W. VON WAHL, Gebrochene Potenzen eines elliptischen Operators und parabolische Differentialgleichungen in Räumen hölderstetiger Funktionen, Nachr. Akad. Wiss. Göttingen Math.-Phys. Kl. 11 (1972), 231-258.

[55] R.-N. WANG, D.-H. ChEn, T.-J. XIAO, Abstract fractional Cauchy problems with almost sectorial operators, J. Differential Equations 252 (2012), 202-235.

[56] Z. XIA AND M. FAN, Weighted Stepanov-like pseudo almost automorphy and applications, Nonlinear Anal. 75 (2012), 2378-2397.

[57] T.-J. XIAO, J. LiAng, AND J. ZHANG, Pseudo-almost automorphic solutions to semilinear differential equations in Banach spaces, Semigroup Forum 76 (2006), 518-524.

[58] S. Zaidman, Almost-Periodic Functions in Abstract Spaces, Pitman Research Notes in Math., vol. 126, Pitman, Boston, 1985.

[59] M. ZAKI, Almost automorphic solutions of certain abstract differential equations, Ann. Mat. Pura Appl. 101 (1974). 